(C) The Author(s) 2019. This is an Open Access articles, distributed under the terms of the Creative

Commons Attribution licence (http://creativecommons.org/licenses/by/4.0/), which permits unrestricted

re-use, distribution, and reproduction in any medium, provided the original work is properly cited.

\title{
Does breast milk adiponectin affect BMI and cardio-metabolic markers in childhood?
}

\author{
Lenie van Rossem ${ }^{1 *}$, Henriette A. Smit ${ }^{1}$, Eef G. W. M. Lentjes ${ }^{2}$, Inge Maitimu-Smeele ${ }^{2}$, Bert Brunekreef ${ }^{3}$, \\ Gerard H. Koppelman ${ }^{4}$ and Alet H. Wijga ${ }^{5}$ \\ ${ }^{1}$ Julius Center for Health Sciences and Primary Care, University Medical Center Utrecht, Utrecht University, 3508 GA Utrecht, \\ The Netherlands \\ ${ }^{2}$ Department of Clinical Chemistry and Haematology, University Medical Centre Utrecht, Utrecht University, 3508 GA Utrecht, \\ The Netherlands \\ ${ }^{3}$ Institute for Risk Assessment Sciences, Utrecht University, 3508 TD Utrecht, The Netherlands \\ ${ }^{4}$ Department of Pediatric Pulmonology and Pediatric Allergology, Beatrix Children's Hospital, UMCG, GRIAC Research \\ Institute, University of Groningen, 9700 RB Groningen, The Netherlands \\ ${ }^{5}$ Center for Nutrition, Prevention, and Health Services, National Institute for Public Health and the Environment, 3720 BA \\ Bilthoven, The Netherlands
}

(Submitted 27 August 2018 - Final revision received 10 November 2018 - Accepted 29 January 2019 - First published online 27 February 2019$)$

\section{Abstract}

Observational studies suggest that breast-feeding is associated with a more favourable BMI and cardio-metabolic markers, but potential underlying mechanisms are unclear. As serum adiponectin has an important function in adults for glucose and lipid metabolism, we assessed 251 participants of the Prevention and Incidence of Asthma and Mite Allergy birth cohort whether breast milk adiponectin is associated with childhood BMI and cardio-metabolic markers. We measured adiponectin levels in breast milk collected around 3 months after birth of the child and subsequently obtained weight and height repeatedly up to the age of 17 years. A medical examination (including blood pressure, glycated $\mathrm{Hb}$ and cholesterol) was performed at the age of 8,12 and 16 years. We used multivariable mixed models to assess the association between breast milk adiponectin and BMI and cardio-metabolic markers at these ages. In models adjusted for exact age of breast milk collection, maternal age, presence of siblings, maternal BMI, pregnancy weight gain and child's birth weight, each unit increase in log breast milk adiponectin (in ng/ $\mathrm{ml}$ ) was associated with a 0.28 lower BMI $z$ score $(95 \% \mathrm{CI}-0.56,0.00)$ at 3 months. After the age of 1 year, there was a tendency towards a higher BMI $z$ score with increased breast milk adiponectin at some ages, but this pattern was not consistent throughout childhood. There were no associations between breast milk adiponectin and any of the cardio-metabolic markers in childhood. We conclude that in our study with followup until 17 years of age, breast milk adiponectin has no long-term effect on BMI and cardio-metabolic health during childhood.

Key words: Breast milk: Adiponectin: BMI: Cardio-metabolic markers: Growth

Adiponectin is an adipokine involved in several biological processes in the human body and generally known for its antiatherogenic and anti-inflammatory effects ${ }^{(1)}$. A higher serum adiponectin level is associated with lower $\mathrm{CVD}^{(1)}$. Remarkably for an adipokine, it is down-regulated in obese subjects ${ }^{(2)}$.

Adiponectin was discovered to be present in breast milk in $2006^{(3)}$. Obviously, breast milk is important for growth and development of the infant. Infant growth is subsequently associated with later growth and overweight ${ }^{(4,5)}$. Breast milk composition, including adiponectin levels, varies between mothers ${ }^{(6)}$. It is therefore of interest whether these different adiponectin levels in breast milk are associated with infant growth. Earlier epidemiological studies suggested that higher breast milk adiponectin is associated with a lower weight gain in the first 4-6 months of life $e^{(7,8)}$ and with a higher weight gain thereafter ${ }^{(7,9)}$. This resulted in a higher weight for length ${ }^{(9)}$ or increased overweight prevalence $^{(10)}$ at the age of 2 years. Regarding the latter, it is hypothesised that this may be the result of a delayed catch-up growth after the period of active breast-feeding. It is relevant to know whether the higher weight or weight gain after the first year of life associated with adiponectin persists in later childhood as tracking of overweight from childhood to adulthood becomes stronger from the age of 2 years onwards ${ }^{(11)}$. However, little is known about breast milk adiponectin and the development of overweight up to adolescence, apart from one study reporting followup up to the age of 5 years ${ }^{(12)}$.

Breast milk is also associated with long-term health effects ${ }^{(13)}$. This may be because the first period of life is characterised by a

* Corresponding author: L. van Rossem, fax +31 88 7555482, email 1.vanrossem@umcutrecht.nl 
high plasticity, where early exposures can permanently change the function and structure of organs ${ }^{(14)}$. The association between breast milk adiponectin and cardio-metabolic markers has not been reported so far, while we hypothesise that such an association may be plausible, given the role of adiponectin in glucose and lipid metabolism ${ }^{(6,15,16)}$.

In this study, with follow-up until the age of 17 years, we aim to extend the findings from earlier studies and assess whether breast milk adiponectin is associated with lower BMI in the first year of life but with higher BMI thereafter. In addition, we study associations between breast milk adiponectin and cardiometabolic markers (cholesterol, glycated $\mathrm{Hb}$ and blood pressure) throughout childhood.

\section{Methods \\ Study design, setting and study population}

We used the data from a population-based Dutch birth cohort study: the Prevention and Incidence of Asthma and Mite Allergy (PIAMA) Study. Details of the study are described elsewhere $^{(17,18)}$. In short, pregnant women were recruited from the general population during their first antenatal visit. Their children ( $n$ 3963) were born in 1996/1997. Data were collected by questionnaires; one in the third trimester of pregnancy, and postnatally at the age of 3 months, yearly around the child's birthday from age 1 year until the age of 8 years, and thereafter at the ages of 11, 14 and 17 years. In addition, in a subgroup of children, a home visit was performed around the age of 3 months, and extensive medical examinations were performed at the ages of 4, 8, 12 and 16 years. Eligible for the present study were all children from mothers who were still breast-feeding during the home visit around the age of 3 months and were willing and able to produce a breast milk sample. The total study population for analysis consisted of 251 children (223 after excluding missing values on the covariates) (Fig. 1). This study was conducted according to the guidelines laid down in the Declaration of Helsinki, and all procedures involving human subjects were approved by the medical ethics committees of the participating institutes. All parents gave written informed consent.

\section{Outcomes: anthropometrics and cardio-metabolic markers in childhood}

In each questionnaire, parents were asked to report child's weight and height measured by a medical professional during the regular scheduled visits to a youth health centre if this measurement was within the last 3 months. Otherwise parents were asked to measure their child's weight and height themselves without shoes and heavy clothes. Regarding the anthropometrics, BMI was our primary interest as it is an indicator of overweight. BMI was calculated as weight $(\mathrm{kg}) / \mathrm{height}^{2}(\mathrm{~m})$, and age- and sex-specific $z$ scores were calculated according to national reference curves ${ }^{(19)}$. To be able to understand the responsible component of an attained BMI value, we also assessed the weight-for-age $z$ scores, length/height-for-age $z$ scores, and weight-for-length/height $z$ scores as well as weight gain during the first year of life. Weight gain during the first year of life was defined as the difference in absolute weight in kilogram per month between birth and 3 months and between 3 and 12 months. We also obtained measured weight and height at the age of 4, 8, 12 and 16 years of age, during the follow-up visits, which were standardised and taken by a trained field worker. The cardio-metabolic markers were measured at the age of 8,12 and 16 years. Serum total and HDL-cholesterol were determined (Roche Diagnostics). Intra-assay variation was $0 \cdot 8 \%$ for total cholesterol ( $n$ 63), and $0.95 \%$ for HDL ( $n$ 21). HbA1c was measured using the Adams A1c, HA-8160 HPLC Auto analyser (Menarini Diagnostics Benelux). Blood pressure readings were obtained at age 12 and 16 years using an Omron M6 Monitor. Two blood pressure measurements were taken at 5 min intervals. If two consecutive measures differed by $>5 \mathrm{mmHg}$, another measurement was taken. The mean of ( 2 or 3) systolic and diastolic measurements was used in analyses.

\section{Exposure: breast milk adiponectin}

Details of human milk collection have been reported elsewhere ${ }^{(20)}$. In short, mothers were asked to provide two samples of about $2 \mathrm{ml}$ each. There were no restrictions regarding the type of collection (though the mothers were asked to avoid fore or hind milk), method of collection (manual expression or breast pump) or time, but these characteristics were documented. The milk samples were collected between 2 and 35 weeks after birth, but the majority of the breast milk samples (77\%) were obtained between 11 and 18 weeks of delivery. The samples were put into tubes containing $2 \mu \mathrm{l}$ butylated hydroxyl toluene solution $(500 \mu \mathrm{g} / \mathrm{ml})$ to prevent oxidation. Mothers were asked to send the samples immediately after collection to the National Institute of Public Health and the Environment, so the samples could be stored within $1 \mathrm{~d}$ at $-70^{\circ} \mathrm{C}$ until analysis.

\section{Assay}

For breast milk adiponectin analyses, breast milk was centrifuged ( $15 \mathrm{~min}, 21000 \mathrm{~g}$ at $4^{\circ} \mathrm{C}$ ). The fatty layer was discarded. Adiponectin was determined using the adiponectin (human) radioimmunoassay \#HADP-61HK (EMD Millipore Corporation). Lower limit of detection was $0.8 \mathrm{ng} / \mathrm{ml}$. Inter-assay variation was $<5.5 \%$ in the range of $10-70 \mathrm{ng} / \mathrm{ml}(n 10)$.

\section{Covariates}

Maternal pre-pregnancy weight and height were self-reported when the child is of 1 year. Birth weight and gestational age were obtained by questionnaire at 3 months after birth. In these first year questionnaires, also other characteristics were obtained such as maternal education, method of delivery and maternal smoking. At the child's age of 3 months, parents received a form on which they kept records of their child's age in weeks when complementary foods were introduced for the first time. On the same form, parents indicated the child's age in weeks when breast-feeding was ended and when formula feeding was initiated. The form was returned to the study centre around the child's first birthday. 


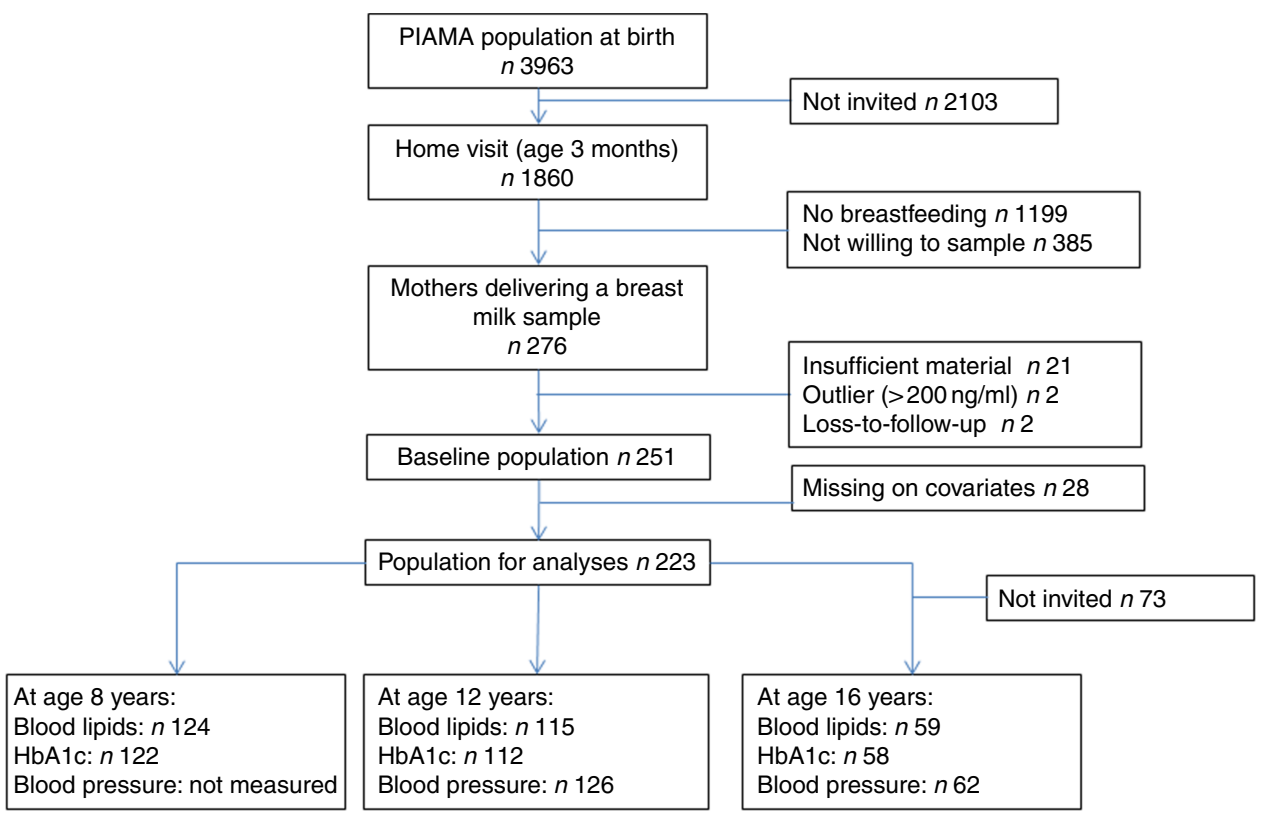

Fig. 1. Flow chart from baseline population to population for analyses and number of children for each cardio-metabolic outcome. PIAMA, Prevention and Incidence of Asthma and Mite Allergy.

\section{Statistical analyses}

We compared baseline characteristics of mothers and children between tertiles of breast milk adiponectin levels. We compared percentages and absolute numbers for categorical variables and tested differences with the $\chi^{2}$ test. We compared means (SD) for continuous variables and tested differences with ANOVA. To assess the association between breast milk adiponectin and the outcome variables (BMI $z$ score, weight-for-age $z$ score, length/height-for-age $z$ score and weight-for-length/ height $z$ score and cardio-metabolic markers), we performed a multivariable mixed model analysis including a random intercept with breast milk adiponectin as the independent variable and BMI $z$ score (continuous) as the dependent variable. The mixed model takes into account the correlation between the BMI $z$ score within each child over time. To obtain age-specific estimates of the association, we added an interaction term for the exposure with age (in years) as a categorical variable. We applied a log transformation to obtain a normal distribution for adiponectin. We checked for non-linear association using penalised splines in $\mathrm{R}$ version 2.10.0. No departure for linearity was observed, and therefore we treated breast milk adiponectin as a continuous variable. Thus, the regression coefficient reflects the increase in BMI $z$ score for each unit increase in log adiponectin (in $\mathrm{ng} / \mathrm{ml}$ ). We adjusted for exact age of breast milk measurement to reduce misclassification of exposure. We identified potential confounders by a combination of a priori considerations and literature ${ }^{(3,6,10,21)}$. We considered maternal age, presence of older siblings, maternal pre-pregnancy BMI, gestational weight gain and birth weight as potential confounders and included these in the adjusted models for BMI $z$ score. To assess the association between adiponectin and weight gain per month during the first year of life, we performed multivariable linear regression analyses. These models were additionally adjusted for child's sex and exact age at weight measurement. We performed sensitivity analyses. First, to take into account breast-feeding duration, we (a) repeated the analysis with an interaction term for adiponectin $\times$ breastfeeding duration and (b) restricted the analyses to those children who were exclusively breast-fed during the first 3 months of life for the analysis of weight gain per month between birth and 3 months. Second, we repeated the analysis with the anthropometrics measured by the investigators instead of parental-measured and -reported anthropometrics.

\section{Results}

The 251 mothers in this study had slightly higher gestational age, higher age and higher BMI compared with remaining PIAMA participants. They also had more often a higher education and smoked less often (Table 1).

Mean breast milk adiponectin level was 15.3 (SD 11.9) ng/ml. Mean maternal age at birth was 30.9 (SD 3.9) years, with a prepregnancy BMI of 22.3 (SD $3 \cdot 1) \mathrm{kg} / \mathrm{m}^{2}$. Birth weight of the child was 3540 (SD 493) g and gestational age was 40.1 (SD 1.4) weeks. Although none of the differences were statistically significant, mothers with breast milk adiponectin in the lowest tertile were slightly older, were less often primiparous and had in general less favourable indicators (i.e. higher BMI, more smoking and gain more often excessive weight). Their children had a slightly higher birth weight (Table 2).

There were no association of breast milk adiponectin with child's age at breast milk collection, sampling time and sampling method (manual, pump, foremilk, hind milk, full milk) (data not shown).

At the age of 3 months, each unit increase in log adiponectin (ng/ml) was associated with a $0 \cdot 30$ (95\% CI -0.57, -0.04) lower BMI $z$ score in crude analysis (Table 3 ). After adjustment, the association attenuated to a $0.28(95 \% \mathrm{CI}-0.56,0 \cdot 00)$ lower BMI 
Table 1. Comparison Prevention and Incidence of Asthma and Mite Allergy (PIAMA) of participants who had adiponectin measured compared with PIAMA participants with no data on adiponectin

(Mean values and standard deviations for continuous variables; numbers and percentages for categorical variables)

\begin{tabular}{|c|c|c|c|c|c|}
\hline & \multicolumn{2}{|c|}{ Adiponectin sample ( $n$ 251) } & \multicolumn{2}{|c|}{ No adiponectin sample ( $n$ 3712) } & \multirow[b]{2}{*}{$P^{*}$} \\
\hline & Mean & SD & Mean & SD & \\
\hline \multicolumn{6}{|l|}{ Maternal characteristics } \\
\hline Maternal age (years) & 30.9 & 3.9 & 30.3 & 3.9 & 0.01 \\
\hline Maternal education & & & & & $<0.0001$ \\
\hline \multicolumn{6}{|l|}{ Low } \\
\hline$n$ & \multicolumn{2}{|c|}{32} & \multicolumn{2}{|c|}{862} & \\
\hline$\%$ & \multicolumn{2}{|c|}{$13 \cdot 0$} & \multicolumn{2}{|c|}{$24 \cdot 2$} & \\
\hline \multicolumn{6}{|l|}{ Middle } \\
\hline$n$ & \multirow{2}{*}{\multicolumn{2}{|c|}{$\begin{array}{r}100 \\
40.5\end{array}$}} & \multicolumn{2}{|c|}{1482} & \\
\hline$\%$ & & & \multicolumn{2}{|c|}{41.6} & \\
\hline \multicolumn{4}{|l|}{ High } & & \\
\hline$n$ & \multirow{2}{*}{\multicolumn{2}{|c|}{$\begin{array}{c}115 \\
46 \cdot 6\end{array}$}} & \multirow{2}{*}{\multicolumn{2}{|c|}{$\begin{array}{l}1216 \\
34.2\end{array}$}} & \\
\hline$\%$ & & & & & \\
\hline Maternal pre-pregnancy BMI $\left(\mathrm{kg} / \mathrm{m}^{2}\right)$ & $22 \cdot 3$ & 3.1 & $22 \cdot 9$ & $3 \cdot 4$ & 0.02 \\
\hline Maternal smoking & & & & & 0.003 \\
\hline$n$ & \multicolumn{2}{|c|}{27} & \multicolumn{2}{|c|}{673} & \\
\hline$\%$ & \multicolumn{2}{|c|}{$10 \cdot 8$} & \multicolumn{2}{|c|}{$18 \cdot 3$} & \\
\hline First child & \multirow{2}{*}{\multicolumn{2}{|c|}{134}} & & & 0.22 \\
\hline$n$ & & & \multicolumn{2}{|c|}{1813} & \\
\hline$\%$ & \multicolumn{2}{|c|}{53.4} & \multicolumn{2}{|c|}{$49 \cdot 2$} & \\
\hline \multicolumn{6}{|l|}{ Perinatal characteristics } \\
\hline Gestational weight gain $\dagger$ & & & & & 0.88 \\
\hline Inadequate & & & & & \\
\hline$n$ & & & & & \\
\hline$\%$ & & & & & \\
\hline Adequate & & & & & \\
\hline$n$ & & & & & \\
\hline$\%$ & & & & & \\
\hline Excessive & & & & & \\
\hline$n$ & & & & & \\
\hline$\%$ & & & & & \\
\hline Caesarean section & & & & & 0.58 \\
\hline$n$ & & & & & \\
\hline$\%$ & & & & & \\
\hline Gestational age (weeks) & 40.1 & 1.4 & 39.8 & 1.7 & 0.003 \\
\hline Birth weight $(\mathrm{g})$ & 3540 & 492 & 3505 & 550 & 0.33 \\
\hline Breast milk characteristics & & & & & \\
\hline Mean breast-feeding duration (weeks) & & & & & \\
\hline Any breast-feeding $\ddagger$ & 29.9 & $12 \cdot 5$ & 13.9 & $14 \cdot 6$ & $<0.0001$ \\
\hline Exclusive breast-feeding & 21.4 & 13.5 & $11 \cdot 2$ & $13 \cdot 3$ & $<0.0001$ \\
\hline
\end{tabular}

* $P$ value for $x^{2}$ test for categorical variables, and for $t$ test for continuous variables.

$\dagger$ According to the criteria of the Institute of Medicine 2009.

$\ddagger$ Any amount of breast-feeding, irrespective of the amount of mixed feeding with infant formula.

$z$ score. From the age of 1 year onwards, children receiving breast milk with a higher level of adiponectin tended to have a higher BMI $z$ score, but this was not consistent throughout childhood, and statistically significant at the age of 4 years only (Table 3). Associations were similar for weight-for-length/height $z$ score (online Supplementary Table S1). Analyses that included an additional term for adiponectin $\times$ breast-feeding duration showed similar associations (data not shown).

Children receiving breast milk with higher levels of adiponectin tended to have a lower weight-for-age $z$ score and a lower length/height-for-age $z$ score, except between 2 and 4 years of age (Table 4). At the age of 3 months, the effect estimate for weight-for-age $z$ score was larger than for length/ height-for-age $z$ score. This reversed after the age of 1 year, where the effect estimate for length/height-for-age $z$ score was larger than for weight-for-age $z$ score.
Each unit increase in log breast milk adiponectin $(\mathrm{ng} / \mathrm{ml})$ was associated with a $0 \cdot 11 \mathrm{~kg} /$ month (95\% CI $-0 \cdot 17,-0.05)$ lower weight gain during the first 3 months of life, while each unit increase in $\log$ adiponectin was associated with a $0.02 \mathrm{~kg} / \mathrm{month}$ (95\% CI -0.00, 0.04) change in weight gain between 3 and 12 months after birth. Estimates for weight gain in the first 3 months were similar when the analyses were restricted to exclusively breast-fed children ( $70 \%$ of the study population, data not shown).

No statistically significant associations were observed between breast milk adiponectin and level of serum lipids, HbA1c or blood pressure at the age of 8, 12 and 16 years (Table 5).

We repeated the analysis for age 4, 8, 12 and 16 years with measured anthropometrics instead of parental measured and -reported anthropometrics, and the associations were similar (Tables 3 and 4 and online Supplementary Table S1). 
Table 2. Baseline characteristics of Prevention and Incidence of Asthma and Mite Allergy participants, total and stratified for tertiles of breast milk adiponectin ( $n$ 251) ${ }^{\star}$ (Mean values and standard deviations for continuous variables; numbers and percentages for categorical variables)

\begin{tabular}{|c|c|c|c|c|c|c|c|c|c|c|}
\hline & \multirow[b]{2}{*}{$n$} & \multicolumn{2}{|c|}{ Total } & \multicolumn{2}{|c|}{ Lowest tertile } & \multicolumn{2}{|c|}{ Middle tertile } & \multicolumn{2}{|c|}{ Highest tertile } & \multirow[b]{2}{*}{$P^{\star}$} \\
\hline & & Mean & SD & Mean & SD & Mean & SD & Mean & SD & \\
\hline \multicolumn{11}{|l|}{ Maternal characteristics } \\
\hline Maternal age (years) & 250 & 30.9 & 3.9 & 31.6 & 3.5 & 30.8 & 3.6 & 30.4 & 4.4 & 0.12 \\
\hline Maternal education & 247 & & & & & & & & & 0.63 \\
\hline Low & & \multirow{3}{*}{\multicolumn{2}{|c|}{$\begin{array}{c}32 \\
13 \cdot 0\end{array}$}} & & & & & & & \\
\hline$n$ & & & & \multicolumn{2}{|c|}{14} & \multicolumn{2}{|c|}{9} & \multicolumn{2}{|c|}{9} & \\
\hline$\%$ & & & & \multicolumn{2}{|c|}{$17 \cdot 1$} & \multicolumn{2}{|c|}{11.0} & \multicolumn{2}{|c|}{$10 \cdot 8$} & \\
\hline Middle & & \multicolumn{2}{|c|}{$13 \cdot 0$} & & & \multirow{2}{*}{\multicolumn{2}{|c|}{34}} & & & \\
\hline$n$ & & \multirow{2}{*}{\multicolumn{2}{|c|}{100}} & \multicolumn{2}{|c|}{29} & & & \multicolumn{2}{|c|}{37} & \\
\hline$\%$ & & & & \multicolumn{2}{|c|}{35.4} & \multicolumn{2}{|c|}{41.5} & \multicolumn{2}{|c|}{44.6} & \\
\hline High & & & $40 \cdot 4$ & & & & & & & \\
\hline$n$ & & & & & & & & & & \\
\hline$\%$ & & & & & & & & & & \\
\hline Maternal pre-pregnancy BMI $\left(\mathrm{kg} / \mathrm{m}^{2}\right)$ & 230 & $22 \cdot 3$ & 3.1 & $22 \cdot 7$ & $3 \cdot 3$ & $22 \cdot 1$ & $2 \cdot 7$ & $22 \cdot 2$ & 3.3 & 0.55 \\
\hline Maternal smoking & 249 & & & & & & & & & 0.88 \\
\hline$n$ & & & & & & & & & & \\
\hline$\%$ & & & & & & & & & & \\
\hline First child & 251 & & & & & & & & & 0.07 \\
\hline$n$ & & & & & & & & & & \\
\hline$\%$ & & & & & & & & & & \\
\hline Perinatal characteristics & & & & & & & & & & \\
\hline $\begin{array}{l}\text { Gestational weight gaint } \\
\text { Inadequate }\end{array}$ & 225 & & & & & & & & & 0.26 \\
\hline$n$ & & & & & & & & & & \\
\hline$\%$ & & & & & & & & & & \\
\hline Adequate & & & & & & & & & & \\
\hline$n$ & & & & & & & & & & \\
\hline$\%$ & & & & & & & & & & \\
\hline Excessive & & & & & & & & & & \\
\hline$n$ & & & & & & & & & & \\
\hline$\%$ & & & & & & & & & & \\
\hline Caesarean section & 250 & & & & & & & & & 0.94 \\
\hline$n$ & & & & & & & & & & \\
\hline$\%$ & & & & & & & & & & \\
\hline Gestational age (weeks) & 251 & 40.1 & 1.4 & 40.2 & 1.3 & $40 \cdot 0$ & 1.4 & $40 \cdot 2$ & 1.5 & 0.79 \\
\hline Birth weight $(\mathrm{g})$ & 251 & 3540 & 493 & 3577 & 481 & 3553 & 520 & 3489 & 477 & 0.48 \\
\hline Breast milk characteristics & & & & & & & & & & \\
\hline Breast milk adiponectin (ng/ml) & 251 & $15 \cdot 3$ & 11.9 & 8.5 & 1.7 & $12 \cdot 8$ & 1.4 & 24.4 & $16 \cdot 7$ & $<0.0001$ \\
\hline Timing of breast milk collection in days after birth & 248 & 107 & 28 & 108 & 32 & 106 & 22 & 109 & 30 & 0.78 \\
\hline Mean breast-feeding duration (weeks) & & & & & & & & & & \\
\hline Any breast-feeding $\ddagger$ & 251 & $30 \cdot 0$ & 12.5 & 31.7 & $13 \cdot 0$ & 27.4 & 11.4 & 30.7 & $12 \cdot 7$ & 0.07 \\
\hline Exclusive breast-feeding & 220 & 21.4 & 13.5 & 23.0 & 14.3 & 19.8 & $12 \cdot 6$ & 21.3 & $13 \cdot 3$ & 0.37 \\
\hline
\end{tabular}

* $P$ value for $x^{2}$ test for categorical variables, and for ANOVA for continuous variables.

† According to the criteria of the Institute of Medicine 2009 .
₹ Any amount of breast-feeding, irrespective of the amount of mixed feeding with infant formula. 
Table 3. Association between breast milk adiponectin and BMI $z$ score throughout childhood, at different ages $\dagger$

\begin{tabular}{|c|c|c|c|c|c|c|c|c|}
\hline \multirow{3}{*}{$\frac{\text { Age }}{3 \text { months }}$} & \multicolumn{4}{|c|}{$\begin{array}{c}\text { Crude change in BMl } z \text { score/ng per } \mathrm{ml} \text { increase in log } \\
\text { adiponectin }(n \text { 251) }\end{array}$} & \multicolumn{4}{|c|}{$\begin{array}{l}\text { Adjusted change in BMI } z \text { score/ng per } \mathrm{ml} \text { increase in log adiponectin } \\
\qquad(95 \% \mathrm{Cl})(n 223)\end{array}$} \\
\hline & \multicolumn{2}{|c|}{ Self-reported } & \multicolumn{2}{|c|}{ Measured } & \multicolumn{2}{|c|}{ Self-reported } & \multicolumn{2}{|r|}{ Measured } \\
\hline & $-0.30^{*}$ & $-0.57,-0.04$ & & NA & -0.28 & $-0.56,0.00$ & & NA \\
\hline 1 year & -0.02 & $-0.25,0.21$ & & NA & $0 \cdot 10$ & $-0.17,0.37$ & & NA \\
\hline 2 years & -0.04 & $-0.30,0.22$ & & NA & 0.11 & $-0.17,0.38$ & & NA \\
\hline 3 years & -0.02 & $-0.24,0.20$ & & NA & 0.07 & $-0.17,0.31$ & & NA \\
\hline 4 years & 0.19 & $-0.04,0.41$ & 0.08 & $-0.13,0.30$ & $0.25^{\star}$ & $0.01,0.49$ & 0.21 & $-0.03,0.45$ \\
\hline 5 years & -0.23 & $-0.47,0.02$ & & NA & -0.13 & $-0.39,0.12$ & & NA \\
\hline 6 years & 0.11 & $-0.12,0.33$ & & NA & $0 \cdot 18$ & $-0.04,0.40$ & & NA \\
\hline 7 years & -0.03 & $-0.32,0.25$ & & NA & 0.01 & $-0.28,0.30$ & & NA \\
\hline 8 years & -0.21 & $-0.58,0.16$ & 0.01 & $-0.19,0.21$ & -0.15 & $-0.53,0.23$ & 0.10 & $-0.09,0.30$ \\
\hline $11 / 12$ years & -0.16 & $-0.44,0.11$ & -0.06 & $-0.38,0.26$ & -0.12 & $-0.39,0.15$ & 0.02 & $-0.30,0.33$ \\
\hline 14 years & -0.13 & $-0.44,0.19$ & & NA & -0.08 & $-0.39,0.23$ & & NA \\
\hline $16 / 17$ years & 0.09 & $-0.27,0.45$ & -0.03 & $-0.68,0.63$ & 0.12 & $-0.26,0.50$ & -0.02 & $-0.70,0.66$ \\
\hline Overall estimate & -0.06 & $-0.23,0.11$ & 0.02 & $-0.18,0.23$ & 0.09 & $-0.17,0.19$ & 0.11 & $-0 \cdot 10,0.32$ \\
\hline
\end{tabular}

NA, not applicable

${ }^{*} P<0.05$.

† Association was adjusted for exact age of breast milk collection, maternal age, presence of siblings, maternal BMI, pregnancy weight gain and child's birth weight. Correlation between repeated measurements within the same children were taken into account with mixed models. The number of observations at each specific age for self-reported BMI $z$ from 3 months to 17 years were $188,213,205,214,193,173,175,161,164,153,149,120$, respectively.

Table 4. Association between breast milk adiponectin and weight-for-age and length/height-for age $z$ score throughout childhood, at different ages $\dagger$

\begin{tabular}{|c|c|c|c|c|c|c|c|c|}
\hline \multirow{2}{*}{$\frac{\text { Age }}{3 \text { months }}$} & \multicolumn{2}{|c|}{$\begin{array}{l}\text { Crude change in weight-for- } \\
\text { age } z \text { score/ng per ml } \\
\text { increase in log adiponectin }\end{array}$} & \multicolumn{2}{|c|}{$\begin{array}{l}\text { Adjusted change in weight- } \\
\text { for-age } z \text { score/ng per } \mathrm{ml} \\
\text { increase in log adiponectin }\end{array}$} & \multicolumn{2}{|c|}{$\begin{array}{l}\text { Crude change in length/ } \\
\text { height-for-age } z \text { score/ng per } \\
\mathrm{ml} \text { increase in log adiponectin }\end{array}$} & \multicolumn{2}{|c|}{$\begin{array}{l}\text { Adjusted change in length/ } \\
\text { height-for-age } z \text { score/ng per } \\
\text { ml increase in log adiponectin }\end{array}$} \\
\hline & $-0.38^{\star *}$ & $-0.66,-0.11$ & $-0.38^{* *}$ & $-0.62,-0.15$ & -0.17 & $-0.47,0.12$ & -0.19 & $-0.45,0.07$ \\
\hline 1 year & -0.10 & $-0.32,0.12$ & -0.08 & $-0.29,0.13$ & $-0 \cdot 13$ & $-0.42,0.15$ & -0.24 & $-0.50,0.03$ \\
\hline 2 years & 0.08 & $-0.16,0.32$ & 0.14 & $-0.08,0.36$ & 0.15 & $-0.16,0.45$ & 0.08 & $-0.21,0.38$ \\
\hline 3 years & 0.05 & $-0.19,0.29$ & 0.08 & $-0.16,0.31$ & 0.09 & $-0.20,0.37$ & 0.03 & $-0.26,0.32$ \\
\hline 4 years & 0.07 & $-0.18,0.32$ & 0.09 & $-0.15,0.32$ & $-0 \cdot 11$ & $-0.41,0.18$ & -0.15 & $-0.43,0.13$ \\
\hline 4 years measured & 0.04 & $-0.20,0.28$ & $0 \cdot 10$ & $-0.13,0.34$ & -0.03 & $-0.28,0.22$ & -0.08 & $-0.32,0.16$ \\
\hline 5 years & -0.20 & $-0.43,0.03$ & -0.19 & $-0.39,0.02$ & -0.16 & $-0.44,0.11$ & -0.22 & $-0.47,0.03$ \\
\hline 6 years & -0.05 & $-0.27,0.17$ & -0.02 & $-0.22,0 \cdot 17$ & -0.20 & $-0.48,0.07$ & -0.24 & $-0.51,0.03$ \\
\hline 7 years & -0.13 & $-0.36,0.09$ & -0.12 & $-0.33,0.08$ & -0.18 & $-0.44,0.07$ & -0.23 & $-0.47,0.01$ \\
\hline 8 years & -0.23 & $-0.49,0.03$ & -0.23 & $-0.47,0.02$ & -0.18 & $-0.44,0.08$ & -0.25 & $-0.50,0.00$ \\
\hline 8 years measured & -0.11 & $-0.33,0.11$ & -0.08 & $-0.28,0 \cdot 12$ & -0.21 & $-0.46,0.04$ & -0.26 & $-0.50,-0.03$ \\
\hline 11 years & $-0.25^{\star}$ & $-0.49,-0.02$ & $-0.25^{\star}$ & $-0.46,-0.03$ & $-0.35^{\star}$ & $-0.62,-0.08$ & $-0.40^{\star *}$ & $-0.65,-0.14$ \\
\hline 12 years measured & -0.17 & $-0.44,0.11$ & -0.13 & $-0.40,0.13$ & -0.29 & $-0.54,-0.04$ & -0.35 & $-0.60,-0.09$ \\
\hline 14 years & -0.14 & $-0.41,0.14$ & -0.17 & $-0.43,0.08$ & -0.26 & $-0.53,0.00$ & -0.32 & $-0.59,-0.05$ \\
\hline 16 years measured & -0.08 & $-0.53,0.37$ & $-0 \cdot 10$ & $-0.53,0.33$ & -0.28 & $-0.66,0.09$ & -0.32 & $-0.70,0.05$ \\
\hline 17 years & 0.02 & $-0.25,0.30$ & 0.00 & $-0.28,0.28$ & -0.17 & $-0.47,0.13$ & -0.24 & $-0.53,0.06$ \\
\hline Overall estimate & $-0 \cdot 11$ & $-0.31,0.08$ & $-0 \cdot 10$ & $-0.28,0.13$ & -0.13 & $-0.37,0.10$ & -0.19 & $-0.41,0.02$ \\
\hline Overall estimate measured & -0.06 & $-0.29,0.17$ & -0.04 & $-0.24,0 \cdot 17$ & $-0 \cdot 16$ & $-0.40,0.07$ & -0.23 & $-0.45,-0.00$ \\
\hline
\end{tabular}

${ }^{*} P<0.05 ;{ }^{* \star} P<0.01$.

$\dagger$ Associations were adjusted for exact age of breast milk collection, maternal age, presence of siblings, maternal BMI, pregnancy weight gain and child's birth weight. Correlation between repeated measurements within the same children were taken into account with mixed models.

\section{Discussion}

A relative high content of adiponectin in breast milk was associated with a lower BMI $z$ score and lower weight-for-age $z$ score at the age of 3 months, and a lower weight gain between birth and 3 months of age. Between the age of 1 and 17 years, children exposed to a relatively high content of adiponectin in breast milk tended to be lighter for their age as well as shorter for their age as compared with children exposed to a low breast milk adiponectin content. The combination of relatively low weight-for-age and relatively low length/height-for-age $z$ scores resulted in BMI values that were neither consistently lower nor consistently higher in the children with a relatively high content of adiponectin in breast milk. Breast milk adiponectin was not associated with cardio-metabolic markers in childhood.

\section{Methodological considerations}

The large number of repeated measurements of weight and height during childhood allowed us to provide a detailed picture of the development of the potential association up to adolescence. We were also able to assess potential confounding due to characteristics that have been described in the literature to affect breast milk adiponectin, including maternal overweight and method of delivery ${ }^{(22)}$. However, some limitations should be addressed. Some misclassification of breast milk adiponectin levels may be present since we collected only one sample of breast milk from the study, and milk collection was not strictly standardised according to the time of the day or fore or hind milk to decrease the burden on the participants. Although we have information on breast-feeding duration and exclusivity, we 
Table 5. Association between breast milk adiponectin and cardio-metabolic markers at age 8,12 and 16 years*

\begin{tabular}{|c|c|c|c|}
\hline Outcome & $n$ & $\begin{array}{l}\text { Change in each unit of the cardio-metabolic } \\
\text { marker/ng per } \mathrm{ml} \text { increase in log adiponectin }\end{array}$ & $95 \% \mathrm{Cl}$ \\
\hline \multicolumn{4}{|l|}{ Blood lipids (mmol) } \\
\hline \multicolumn{4}{|c|}{ Total cholesterol (mmol) } \\
\hline Age 8 years & 124 & 0.05 & $-0.16,0.25$ \\
\hline Age 12 years & 115 & -0.14 & $-0.33,0.06$ \\
\hline Age 16 years & 59 & 0.13 & $-0.25,0.51$ \\
\hline Overall estimate & & -0.02 & $-0.21,0,17$ \\
\hline \multicolumn{4}{|l|}{$\mathrm{HDL}(\mathrm{mmol})$} \\
\hline Age 8 years & 124 & 0.05 & $-0.06,0.17$ \\
\hline Age 12 years & 115 & -0.05 & $-0.14,0.05$ \\
\hline Age 16 years & 59 & 0.10 & $-0.06,0.26$ \\
\hline Overall estimate & & 0.02 & $-0.07,0.11$ \\
\hline \multicolumn{4}{|l|}{ TAG (mmol) } \\
\hline Age 16 years & 59 & -0.30 & $-0.68,0.08$ \\
\hline \multicolumn{4}{|l|}{ HbA1c (\%) } \\
\hline Age 8 years & 122 & -0.09 & $-0.21,0.05$ \\
\hline Age 12 years & 112 & 0.04 & $-0.05,0.13$ \\
\hline Age 16 years & 58 & 0.85 & $-0.53,2.23$ \\
\hline Overall estimate & & 0.60 & $-1.49,2.69$ \\
\hline \multicolumn{4}{|c|}{ Blood pressure $(\mathrm{mmHg})$} \\
\hline \multicolumn{4}{|l|}{ Systolic (mmHg) } \\
\hline Age 12 years & 126 & $2 \cdot 38$ & $-0.73,5.48$ \\
\hline Age 16 years & 62 & $1 \cdot 17$ & $-4 \cdot 18,6 \cdot 51$ \\
\hline Overall estimate & & $2 \cdot 13$ & $-0.64,4.89$ \\
\hline \multicolumn{4}{|l|}{ Diastolic (mmHg) } \\
\hline Age 12 years & 126 & 0.65 & $-1.51,2.81$ \\
\hline Age 16 years & 62 & -0.81 & $-4.02,2.40$ \\
\hline Overall estimate & & 0.37 & $-1.77,2.51$ \\
\hline
\end{tabular}

do not know the overall breast milk volume and therefore lack information on the total amount of exposure to adiponectin in the breast-feeding period. It is likely that other hormones such as leptin and insulin are important for body composition as well. It was not possible to analyse these hormones in our samples, and therefore our inference is restricted to solely one metabolite. Although weight and length/height were measured during the medical examinations at age 4, 8, 12 and 16 years, we used the weight and length/height obtained by the questionnaires, because of the higher frequency of these data in the early years. We reported on the validity of self-reported $v$. measured height and weight and concluded that BMI measured and reported by the parents is a valid alternative for observed $\mathrm{BMI}^{(23,24)}$. Although loss to follow-up was present in our study, it would only lead to bias if children exposed to a low or high breast milk adiponectin level and a specific growth trajectory would be more often lost to follow up. It is unlikely that this has occurred. However, the smaller number of observations in older children have affected the precision of our estimates, resulting in wider confidence intervals around the estimates. Lastly, we do not have information on maternal BMI at the exact moment of breast milk sampling. Therefore, we used maternal pre-pregnancy BMI as a proxy. This may have resulted in some misclassification.

\section{Underlying mechanism}

The correlation between maternal serum adiponectin and breast milk adiponectin suggests that mammary epithelial cells have a role in secreting adiponectin in breast milk, either by new synthesis or by transferring it from maternal serum ${ }^{(25)}$. In addition, it is fully absorbed by the infant's digestive tract, making a biological function plausible ${ }^{(6,22)}$. This biological function may be related to weight gain as higher adiponectin content of breast milk was suggested to decrease gastric emptying in fully breast-fed infants ${ }^{(26)}$. Gastric emptying rate is associated with satiety, which in turn influences growth via energy intake. Although we did not observe a clear and consistent long-term effect of breast milk adiponectin on BMI in later childhood, this single observation does not rule out that breast milk adiponectin may be an important hormone for long-term health. It was hypothesised that breast milk adiponectin only expresses its function during the period of active breast-feeding. After stopping breast-feeding, there may be a delayed 'catch-up growth'. As opposed to early catch-up growth, later 'catch-up growth' may result in relatively more lean mass than fat mass ${ }^{(9)}$. Indeed, we observed lower weight gain during the first 3 months, which was not observed between 3 months and 1 year, the period where most mothers stop breast-feeding. This biological path should be further explored. It would be interesting to elucidate the potential link between pregnancy adiponectin levels and breast milk adiponectin $^{(25,27,28)}$, as we noticed differences in birth weight between the children born to mothers in the different breast milk adiponectin tertiles. Although we adjusted for birth weight in the analyses, we do not exclude the possibility that maternal exposures during pregnancy influence birth weight as well as breast milk adiponectin. Future studies can shed more light on the interactions between maternal adiponectin 
level during pregnancy, breast milk adiponectin and childhood serum adiponectin in relation to anthropometry in childhood. For now, despite its potential importance of regulating infancy growth, adiponectin seems not to be a target component for optimising infant feeding and prevent childhood overweight.

\section{Comparison with earlier studies}

Breast milk adiponectin levels were comparable with concentrations found in earlier studies ${ }^{(3,7-10,29-32)}$. Some differences in adiponectin levels may be explained by differences in maternal characteristics. It was reported that breast milk adiponectin levels were associated with maternal factors such as BMI, ethnicity and lactation duration ${ }^{(3,30)}$.

Our finding that high breast milk adiponectin is associated with lower BMI $z$ score and weight-for-age at age 3 months is comparable with earlier studies that have reported about breast milk adiponectin and infant weight-for-length and weight-forage in the first year of life ${ }^{(8,31)}$. Also, the lower weight gain in the first 3 months of life has been reported before ${ }^{(7)}$.

Earlier studies about BMI development after this first year are inconsistent. Some studies reported that the association reversed after the first year of life, with increasing weight-forage and weight-for-length $z$ scores until the age of 2 years ${ }^{(9)}$ or higher overweight risk at the age of 2 years ${ }^{(10)}$ with higher adiponectin levels. However, one follow-up study did not report an association between adiponectin and weight, BMI or fat mass after the age of 3 years ${ }^{(12)}$. The lower height-for-age $z$ score in our results was not reported earlier ${ }^{(9)}$, and we have no explanation for this. We extend previous findings by reporting that children who received breast milk with a relatively high content of breast milk adiponectin tended to have lower weight-for-age and height-for-age between the age of 1 and 17 years, which resulted in no consistent association with BMI in childhood. Future studies have to confirm our findings and would ideally include repeated serum measurements of adiponectin as well as measurements of body fat.

To our knowledge, there are no previous studies to compare our results with regarding the cardio-metabolic markers. Adiponectin increases insulin sensitivity. Earlier studies showed that serum adiponectin in childhood is associated with measures of insulin and glucose $\mathrm{e}^{(33)}$. It has been suggested that serum adiponectin may serve as a biomarker for the metabolic syndrome. Similar to the BMI outcomes, breast milk adiponectin may therefore only have an immediate effect on cardio-metabolic indicators but does not exert a programming and thus long-term effect on glucose and lipid metabolism, which may explain that we did not find an association between breast milk adiponectin and later cardiometabolic markers.

\section{Conclusion}

A higher content of adiponectin in breast milk is associated with lower BMI and lower weight gain in early infancy, but we observed no long-term effect of breast milk adiponectin on BMI or cardio-metabolic markers after the age of 1 year up to the age of 17 years.

\section{Acknowledgements}

The authors thank the PIAMA participants for their ongoing collaboration.

This study was supported by the Netherlands Heart Foundation (L. v. R., grant no. 2013T025). The PIAMA study was supported by the Netherlands Organization for Health Research and Development; The Netherlands Organization for Scientific Research; The Netherlands Lung Fund; The Netherlands Ministry of Spatial Planning, Housing, and the Environment; The Netherlands Ministry of Health, Welfare, and Sport. The funders had no role in the design, analysis or writing of this article.

L. v. R. conceptualised and designed the study and drafted the initial manuscript. A. H. W. and H. A. S. contributed to acquisition of data, interpretation of the data, reviewed and revised the manuscript. E. G. W. M. L. and I. M.-S. contributed to data analysis and interpretation, and critically reviewed the manuscript. B. B. and G. H. K. contributed to data acquisition for the study and critically reviewed the manuscript. All authors approved the final manuscript as submitted.

The authors declare that there are no conflicts of interest.

\section{Supplementary material}

For supplementary material/s referred to in this article, please visit https://doi.org/10.1017/S0007114519000266

\section{References}

1. Turer AT \& Scherer PE (2012) Adiponectin: mechanistic insights and clinical implications. Diabetologia 55, 2319-2326.

2. Arita Y, Kihara S, Ouchi N, et al. (1999) Paradoxical decrease of an adipose-specific protein, adiponectin, in obesity. Biochem Biophys Res Commun 257, 79-83.

3. Martin LJ, Woo JG, Geraghty SR, et al. (2006) Adiponectin is present in human milk and is associated with maternal factors. Am J Clin Nutr 83, 1106-1111.

4. Matthews EK, Wei J \& Cunningham SA (2017) Relationship between prenatal growth, postnatal growth and childhood obesity: a review. Eur J Clin Nutr 71, 919-930.

5. Singhal A (2017) Long-term adverse effects of early growth acceleration or catch-up growth. Ann Nutr Metab $\mathbf{7 0}$, 236-240.

6. Newburg DS, Woo JG \& Morrow AL (2010) Characteristics and potential functions of human milk adiponectin. J Pediatr $\mathbf{1 5 6}$, S41-S46.

7. Brunner S, Schmid D, Zang K, et al. (2015) Breast milk leptin and adiponectin in relation to infant body composition up to 2 years. Pediatr Obes 10, 67-73.

8. Woo JG, Guerrero ML, Altaye M, et al. (2009) Human milk adiponectin is associated with infant growth in two independent cohorts. Breastfeed Med 4, 101-109.

9. Woo JG, Guerrero ML, Guo F, et al. (2012) Human milk adiponectin affects infant weight trajectory during the second year of life. I Pediatr Gastroenterol Nutr $\mathbf{5 4}$, 532-539. 
10. Weyermann M, Brenner H \& Rothenbacher D (2007) Adipokines in human milk and risk of overweight in early childhood: a prospective cohort study. Epidemiology 18, 722-729.

11. Singh AS, Mulder C, Twisk JW, et al. (2008) Tracking of childhood overweight into adulthood: a systematic review of the literature. Obes Rev 9, 474-488.

12. Meyer DM, Brei C, Stecher L, et al. (2017) The relationship between breast milk leptin and adiponectin with child body composition from 3 to 5 years: a follow-up study. Pediatr Obes 12, Suppl. 1, 125-129.

13. Robinson SM (2015) Infant nutrition and lifelong health: current perspectives and future challenges. J Dev Orig Health Dis 6, 384-389.

14. Hanson MA \& Gluckman PD (2014) Early developmental conditioning of later health and disease: physiology or pathophysiology? Physiol Rev 94, 1027-1076.

15. Savino F, Petrucci E \& Nanni G (2008) Adiponectin: an intriguing hormone for paediatricians. Acta Paediatr 97, 701-705.

16. Kratzsch J, Bae YJ \& Kiess W (2018) Adipokines in human breast milk. Best Pract Res Clin Endocrinol Metab 32, 27-38.

17. Brunekreef B, Smit J, de Jongste J, et al. (2002) The prevention and incidence of asthma and mite allergy (PIAMA) birth cohort study: design and first results. Pediatr Allergy Immunol 13, Suppl. 15, 55-60.

18. Wijga AH, Kerkhof M, Gehring U, et al. (2014) Cohort profile: the prevention and incidence of asthma and mite allergy (PIAMA) birth cohort. Int J Epidemiol 43, 527-535.

19. Fredriks AM, van BS, Burgmeijer RJ, et al. (2000) Continuing positive secular growth change in the Netherlands 1955-1997. Pediatr Res 47, 316-323.

20. Wijga A, Houwelingen AC, Smit HA, et al. (2003) Fatty acids in breast milk of allergic and non-allergic mothers: the PIAMA birth cohort study. Pediatr Allergy Immunol 14, 156-162.

21. Ley SH, Hanley AJ, Sermer M, et al. (2012) Associations of prenatal metabolic abnormalities with insulin and adiponectin concentrations in human milk. Am J Clin Nutr 95, 867-874.

22. Fields DA, Schneider CR \& Pavela G (2016) A narrative review of the associations between six bioactive components in breast milk and infant adiposity. Obesity (Silver Spring) 24, 1213-1221.
23. Bekkers MB, Brunekreef B, Scholtens S, et al. (2011) Parental reported compared with measured waist circumference in 8-year-old children. Int J Pediatr Obes 6 , e78-e86.

24. Scholtens S, Brunekreef B, Visscher TL, et al. (2007) Reported versus measured body weight and height of 4-year-old children and the prevalence of overweight. Eur J Public Health 17, 369-374.

25. Weyermann M, Beermann C, Brenner H, et al. (2006) Adiponectin and leptin in maternal serum, cord blood, and breast milk. Clin Chem 52, 2095-2102.

26. Gridneva Z, Kugananthan S, Hepworth AR, et al. (2017) Effect of human milk appetite hormones, macronutrients, and infant characteristics on gastric emptying and breastfeeding patterns of term fully breastfed infants. Nutrients $\mathbf{9}, 15$.

27. Dundar NO, Dundar B, Cesur G, et al. (2010) Ghrelin and adiponectin levels in colostrum, cord blood and maternal serum. Pediatr Int 52, 622-625.

28. Fujimori M, Franca EL, Morais TC, et al. (2017) Cytokine and adipokine are biofactors can act in blood and colostrum of obese mothers. Biofactors 43, 243-250.

29. Bronsky J, Karpisek M, Bronska E, et al. (2006) Adiponectin, adipocyte fatty acid binding protein, and epidermal fatty acid binding protein: proteins newly identified in human breast milk. Clin Chem 52, 1763-1770.

30. Bronsky J, Mitrova K, Karpisek M, et al. (2011) Adiponectin, AFABP, and leptin in human breast milk during 12 months of lactation. J Pediatr Gastroenterol Nutr 52, 474-477.

31. Chan D, Goruk S, Becker AB, et al. (2017) Adiponectin, leptin and insulin in breast milk: associations with maternal characteristics and infant body composition in the first year of life. Int J Obes (Lond) 42, 36-43.

32. Savino F, Lupica MM, Benetti S, et al. (2012) Adiponectin in breast milk: relation to serum adiponectin concentration in lactating mothers and their infants. Acta Paediatr 101, 1058-1062.

33. Pyrzak B, Ruminska M, Popko K, et al. (2010) Adiponectin as a biomarker of the metabolic syndrome in children and adolescents. Eur J Med Res 15, Suppl. 2, 147-151. 